\title{
The Health and Well-Being among Children with Diabetes and Low HbA1c-A Qualitative Study in Sweden
}

\author{
Lena Lendahls ${ }^{1,2}$, Ingrid Edvardsson ${ }^{1,3}$ \\ ${ }^{1}$ Department of Research and Development, Kronoberg County Council, Kronoberg County, Sweden \\ ${ }^{2}$ Department of Health and Caring Sciences, Linnaeus University, Kalmar, Sweden \\ ${ }^{3}$ Department of Clinical Sciences Malmö, Lund University, Lund, Sweden \\ Email: lena.lendahls@lnu.se
}

How to cite this paper: Lendahls, L. and Edvardsson, I. (2018) The Health and Well-Being among Children with Diabetes and Low HbAlc-A Qualitative Study in Sweden. Health, 10, 551-564.

https://doi.org/10.4236/health.2018.105044

Received: April 7, 2018

Accepted: May 18, 2018

Published: May 21, 2018

Copyright $\odot 2018$ by authors and Scientific Research Publishing Inc. This work is licensed under the Creative Commons Attribution International License (CC BY 4.0).

http://creativecommons.org/licenses/by/4.0/

\begin{abstract}
Aims and objectives: To examine health and well-being, as well as the need for support among children and parents where the child has T1DM with low $\mathrm{HbAlc}(<52 \mathrm{mmol} / \mathrm{mole})$. The purpose was also to investigate the extent to which children's and parents' experiences match. Introduction: Studies have shown that children with diabetes type 1 (T1DM) rate their lives as worse than healthy peer ratings. In Sweden, views have been expressed that children, as well as their parents, feel pressurized by the diabetes teams to achieve low $\mathrm{HbAlc}$ values, which can lead to poorer mental health for the family. Design: A qualitative study. Methods: A consecutive sample of 11 children and their parents (one father, ten mothers) was interviewed together but individually guided by a semi structured interview guide. Interviews were analyzed using thematic content analysis. Results: Four main categories were consistent across children and their parents; 1) attitude to the illness, 2) sadness about diabetes, 3) the importance of the social network, and 4) the importance of the diabetes team. Worries about hyperglycemia were more prominent than worries about hypoglycemia in both children and parents. A distinguishing feature of the interviewed children was that they were responsible, strict and targeted. Many of them were competitive and took part in various sports, even at a very advanced level. Conclusions: This study shows that children with low HbAlc values experience good health and good well-being. Family support, good planning, and high acceptance of their illness contributed to this.
\end{abstract}

\section{Keywords}

Diabetes, Children, Health, Well-Being, Low HbA1c, Qualitative Study 


\section{Introduction}

The mission of diabetes care is to promote good health and life quality both short-term and long-term for people with diabetes. HbAlc is an important marker for the risk of developing future complications [1]. In 2016, Swedish 17 -year-olds with diabetes had an average $\mathrm{HbAlc}$ of $61 \mathrm{mmol} / \mathrm{mol}$. This is worrying since the highest recommended target value according to NICE guidelines should not exceed $48 \mathrm{mmol} / \mathrm{mol}$. Today, an increasing number of Swedish children with diabetes has access to an insulin pump and CGM (continuous glucose monitoring), which has led to decreasing HbAlc-levels compared to previous years [2].

To be diagnosed with diabetes means lifestyle changes that may lead to both emotional and social consequences [3]. Many children with diabetes feel different, lonesome and excluded at school and among their friends. They want to be normal and be treated as a person without diabetes. Sometimes, this leads to avoid telling others that they are suffering from diabetes [4]. To be subjected to treatments and restrictions around the diet creates an inner tension in the children that makes them feel worried about blood sugar levels, but they still want to do what everyone else does and therefore do not want to eat or care about the restrictions. They may also feel that needles and pricks cause fear, pain and insecurity, which affects their ability to check blood sugar levels and administer insulin [5].

Studies have shown that children with diabetes type 1 (T1DM) rate their lives as worse than healthy peer ratings. Those who had high HbAlc values rated their lives worst and had more depressive symptoms and behavior problems [6] [7] However, an international study shows that low HbAlc values were associated with higher health-related quality of life scores. This was primarily true for the youngest people ( 8 - 18 years) and boys. Furthermore, the results showed that measuring your food intake, measuring your blood sugar level more frequently, and exercising 30 minutes or more several times a week was linked to life quality among adolescents with T1DM [8].

There are high demands on parents of children with diabetes, which in the beginning means constant planning of meals, insulin intake and activities, etc. [5] [9]. These changes affect the entire family and often continue for a long time [5].

Parents report that they feel worry and fear of both short- and long-term consequences of the illness [10] [11]. The worry was more pronounced during the first years after diagnosis, but as time went they became more experienced and new situations arose more seldom, which reduced the stress and anxiety [10]. Parents of both younger and older children report a constant worry of hypoglycemia and feelings of panic from just thinking about it [12] [13]. This was particularly the case during the night, when the child could suffer from hypoglycemia while sleeping and never wake up anymore [11] [14]. These parents often felt tired and exhausted because they did not sleep well and sometimes set an 
alarm to check their children [14].

Parents report that they had difficulty transferring the responsibility for the child to other people [15], such as the daycare or school staff [11] [16]. They gave information and tried to convey knowledge about diabetes to teachers to enable them to handle an emergency situation. They considered the school an important environment where the children should learn to interact with their friends and teachers, but at the same time they felt the planning at school was difficult. Therefore, the parents supervised their child until they knew that the child could handle its illness on its own [11] [12].

One study shows that parents underrated their children's health-related quality of life (HRQOL) from the age of 8 compared to the children's own rating. However, parents and children were more consistent when the children were 5 to 7 years old [17]. Family studies have shown that parents' involvement in diabetes treatment is often lower when their children are in their early teens, but that adolescents with good parental support to a greater degree achieve satisfactory glycemic control [18].

In Sweden, views have been expressed that children, as well as their parents, feel pressurized by the diabetes teams to achieve low HbAlc values, which can lead to poorer mental health for the family [19]. Therefore, the diabetes team in the current county expressed a wish to examine health and well-being, as well as the need for support among children and parents where the child has T1DM with low HbAlc values $(<52 \mathrm{mmol} / \mathrm{mol})$. The purpose was also to investigate the extent to which children's and parents' experiences match.

\section{Methods}

\section{Participants and procedure}

The study was performed at a Pediatric Diabetes Department unit in the south of Sweden. The participants were Swedish-speaking children aged 11 to 18 years who had been diagnosed with T1DM for a minimum of 12 months, without any severe chronic illness, and with a mean HbAlc $\leq 52 \mathrm{mml} / \mathrm{l}$ in the past year. One of the children's parents was also included in the study.

The diabetes nurse consecutively asked children and the respective parents who met the inclusion criteria if they were interested in taking part in the study. She gave them oral and written information about the purpose of the study, that participation was voluntary and that they could cancel their participation at any time without giving any reason, and that this would not affect their continued contact with the diabetes team. They were also told that children and parents would be interviewed together but individually by the authors in a place they could choose themselves. That participation was confidential and the material would be presented in such a way that no individual could be recognized. One of the authors called the 11 children and parents who were interested in participating within two weeks. Time and place for the interviews were decided. Individual interviews were conducted with the children by author IE and with the par- 
ents by author LL, using a semi-structured interview guide. Questions asked were within the following areas: 1) Everyday life with diabetes; e.g. How much space does your/your child's diabetes in your everyday life? 2) Visits to the diabetes clinic; e.g. Do you worry/do you think your child worries about the information about the HbAlc value? 3) Relationships with friends; e.g. Do you feel that your child's diabetes affects the relationships with friends? 4) Describe how you feel about your life/how do you think your child feels about his/her life?

The interviews were either conducted at the Pediatric Diabetes Clinic (8 interviews), in the participants' homes (2 interviews) and one interview at a parent's workplace. The interviews lasted between 20 and 70 minutes, were recorded and transcribed verbatim.

\subsection{Data Analysis}

The analysis began immediately following the interview, and the authors discussed, summarized and compared their impressions from the interviews with children and parents. The data were then analyzed using a qualitative approach, known as thematic content analysis [20] [21].

The two authors were involved in the entire process of the analysis, and data processing was conducted in several steps. The transcribed material was read carefully and repeatedly by both authors individually to get an idea of the whole picture. Some sentences were highlighted and a short phrase was written down in the margin. These phrases summed up the content of the highlighted sentences. All these phrases were then grouped, and those with a similar content were removed in order to avoid repetition. Finally, the phrases were sorted into four main categories matching the aim of the study.

\subsection{Ethical Considerations}

In all research, especially where children are involved, ethical considerations are required. Children constitute a group that is considered especially vulnerable with regard to conducting research, unless the risks are considered minimal. In conversation with people about their experiences or events in life, sensitive subjects may come up. In this study, it could be unpleasant experiences related to their illness or concern about future complications. To minimize the risks, an open climate was sought between participants and researchers, as well as a safe environment in which the interviews were conducted. If there was a need to discuss issues related to the illness or the care provided, the participants were asked to contact their doctor or nurse.

The study was approved by the Regional Ethics Committee for Human Research, Faculty of Health Sciences at Linköping University, Sweden (Reg. no. 2014/234-31), and performed in accordance with the Helsinki Declaration (WMA Declaration of Helsinki). Written informed consent was obtained from both the children and their parents at the time when the interviews were provided. 


\section{Results}

Four girls and seven boys were interviewed, and the age varied between 11 and 18 years, the average age being 14.5 years. They had suffered from diabetes between three and 16 years, an average of 8.1 years. Ten mothers and one father participated in the study.

\subsection{Attitude to the Illness}

The desire to be like everyone else was strong, despite the diabetes. A majority of them tried to live their lives without restrictions, neither for the child nor for the family. The children tried to live the life they wanted, and they did not want the illness to interfere too much with their lives. It was natural to live with diabetes, and they had adapted to it and were making the most of the situation. The illness became part of them as people, and they experienced diabetes as a good way of life. The body changed due to diabetes-but not their everyday life. When you accepted your illness, you also accepted your limitations, and this made life manageable and diabetes was given priority.

"It is me who will decide on the diabetes, not the diabetes deciding over me." (participant 3, child).

"Everyone feels good about eating at regular times, you know ... so no, I don't think there's anything limiting us." (participant 10, parent).

Parents stated that they had difficulty accepting their child's illness, while the children more easily adapted to it. In an accepting approach, it was easier for the children to talk about the illness with friends or other adults than with the parents. They tried to be pragmatic and solved situations easily and took problems as they came and did not worry in advance. Some had a fatalistic attitude to their diabetes. The children were striving to feel safe and secure so the illness would take as little space as possible in their lives, so that they could live the life they wanted. It was important to easily find a balance between the bind and the freedom. One way to make this easier was to create routines.

"My motto is to live like everybody else and then you get to sort of ... I mean, you have to remember that you have diabetes, but you still have to think that you are like everybody else and then that you have some help as well." (participant 3, child).

"It's not something to ponder over, but I'm on standby all the time, mentally." (participant 6, parent).

For all the children, diabetes was not a natural part of their identity. Some suppressed the illness and did not want to talk about it, as they did not want to be different from their friends. They wanted to ignore their diabetes and did not want to do so many blood sugar tests, but trusted their feelings and did not check so often, or they hid their pump. They wanted to be rational, and they considered it unnecessary to be worried and wanted to make the most of their situation.

"Mmm ... I do not check it very often [the blood sugar level] because I sort of 
have a feel for how I'm doing, so." (participant 9, child).

“... but she thinks it's a bit tough, yes, so that's not something she's talking about then." (participant 11, parent).

Some parents believed that their children thought of complications and that they could die if they did not look after themselves, and that worry was a driving force to take control. The parents also felt that the children wanted to take care of themselves and be independent.

Some parents were also of the opinion that their children felt they had limitations in life. For example, they were unable to eat like others and that things worked differently during physical activities. In these cases, the children were not open about their illness and wanted to hide it from people around them.

... there are things about which she thinks that "I cannot do that." (participant 11, parent).

\subsection{Sadness about Diabetes}

Living with diabetes affected everyday life and took time from other things, especially the first few years after they were diagnosed. Time for planning, always have a packed bag with necessary equipment and extra food, measure blood sugar levels and eat regularly and properly.

"I always have to check my blood sugar level, and I have to eat properly all the time, and things like that; so it's obvious that it takes a lot of space in my life." (participant 4, child).

The children described their daily life as becoming a routine, and their illness took increasingly less space, but at times they became tired of it and wished they could free themselves from the "diabetes".

"... But I can get terribly tired of it." (participant 2, child).

The everyday life of the entire family was affected. Food and meals have to be carefully planned, and there was less space for spontaneous activities. Instead, the family could seek comfort in the fact that everyone felt good at were all eating good food and at regular intervals.

"And sometimes I think that [the diabetes] has shaped our lives." (participant 4, parent).

The younger children and those who had fallen ill recently felt more limited and watched over by their parents compared to the older children. They felt that it was sometimes too much nagging about keeping track of blood sugar levels, and that the parents always wanted to know where they were and who they met. And they were not allowed to be home alone or stay the night with friends. If they were allowed to stay the night, the friend's parents had to be informed.

"... I have not stayed the night with friends yet, because they [the parents] want to wait until I am older and kind of able to take care of myself." (participant 6 , child).

"The first time he was staying the night with a friend, I was worried. Wondering if they would understand what they should do if the level became low and they should call us if something was wrong." (participant 9, parent). 
Most parents interviewed felt that their everyday life was affected and they were forced to have a more planned life than before their children fell ill. Some felt that it affected them more than the children, but they accepted this and made the most of the situation, because they wanted their children to be able to live as normal a life as possible.

"It takes more space for us, and we have to keep a watching eye all the time. Always be on standby." (participant 6, parent).

Both children and parents described their worries about complications. Some of them could talk openly to each other about their worries, while others kept them to themselves. Some parents did not want to show their worry in front of their children, but the children understood their worry, and therefore they kept their own worry to themselves.

My goal is that he should not be aware of my worry." (participant 8, parent).

"I can say that it's probably she [mom] who is worried about me and how I feel." (participant 6, child).

Despite the worry, both children and parents tried to take control of the illness and turn it into something positive. Their goal was to have low blood sugar levels, and thanks to these low HbA1C values they did not have to worry about complications later.

"He is often low, and we keep him very low and we have said that we are going to win the World Cup in diabetes. If a transplant ever may happen, he should be in such good shape that his body is able to receive an organ." (participant 4, parent).

“... I do not do things that are not good for my diabetes. I usually think I'll do what's best for my diabetes." (participant 8 , child).

Worries about hyperglycemia were more prominent than worries about hypoglycemia in both children and parents, even those who never suffered from either of these. One of the younger children told me that she sometimes could not sleep because she was afraid she would need to go to the hospital during the night if the blood sugar level became too high while she slept, although this had never happened.

“... but then you get scared that it has gone up too much, that's what you're worried about." (participant 1, child).

One boy told of how he had changed after suffering from ketoacidosis, and the doctors had told him he had been as close to death as he could get. He had become very scared and realized that if he did not take care of it, it had consequences in both the short- and long-term perspective. This was confirmed by his mother who said that after the incident he became more motivated and careful about monitoring his blood sugar level and take action quickly. She felt that despite the incident, he had become more secure and calm as he had gained knowledge of how to handle his illness.

"When I did not look after myself, I felt bad, but it [the ketoacidosis] made me change as I understood that the hell I could go on like that. I acted and now it's not a problem." (participant 2, child). 
"He is safe and calm with his diabetes, and now I do not need to get involved so much anymore." (participant 2, parent)

\subsection{The Importance of the Social Network}

The importance of the family for handling a life with diabetes is reflected in both child and parent interviews. It is, after all, an illness that not only affects the individual but the entire family.

In families with shared custody, it was mainly one of the parents who took the most responsibility for everything around the illness. The week when the child was with the other parent, it was difficult to relax and not worry.

"I am the one who takes responsibility ... It's always on my mind ... to follow up the blood sugar level and everything is more than what he does." (participant 1 , parent).

Most children said that they got great support from their parents, and the mothers in particular took great responsibility. However, some felt they were overprotective, especially in the early years of the illness. The parents expressed their difficulty in letting go, but they tried to give their children more freedom and responsibility. However, some children felt that they were taking too much responsibility themselves and wanted to hand it over to an adult, at least on some occasions. In these cases, the parents seemed unaware that the children felt like that, and instead they emphasized that the children were very good for their age and managed most things themselves. The children expressed some concern for not living up to the parents' expectations. However, this was not something they talked about with their parents.

"I think the support at the beginning is very important, and I got great support from my parents ... and always had them to lean on." (participant 7, child).

"I'm usually the one who has to work out how much insulin I should take." (participant 10, child).

"She has very good knowledge for her age." (participant 10, parent).

None of the interviewed children was envious of their healthy siblings. Some even said they were grateful that they got the illness, and not one of their siblings. They felt that they were more likely to manage a life with diabetes because they were more careful and targeted than their siblings.

“... to be honest, I don't think about it that much, I've accepted it and everyone should live like a diabetic." (participant 7, child).

For most of the children interviewed, schoolwork was not a problem and they said they were happy and liked going to school. They felt safe, both with their classmates and their teachers. However, something that bothered them was that they came later than their classmates, for example to lunch or sports class because they had to check their blood sugar level or take insulin.

"Yes ... when the blood sugar level is like that ... then I usually measure after lunch, and when I have finished my food, they are already playing football so I cannot join them." (participant 6, child). 
There was an ambivalence regarding what they felt when their friends asked questions. Sometimes, the questions were perceived as them being interested and supportive, while some only asked out of curiosity. Most of them were very open about their illness and gladly told them if they considered it justified. However, someone felt it was hard to talk about their illness with new classmates or teachers, for example when changing class levels/schools.

“... if they have any questions, I will gladly explain." (participant 5, child).

The parents also felt safe when the children were at school and trusted that both teachers and classmates knew what to do if something happened during school time.

A distinguishing feature of the interviewed children was that they were responsible, strict and targeted. Many of them were competitive and took part in various sports, even at a very advanced level. They talked about the balance between foods, training and insulin to feel good and that they had good tools for this. If they were in control, they felt safe and were able to relax. A few saw the illness as a challenge and wanted to perform as well at sports as their healthy friends.

"Check blood sugar levels, think about what you eat and what to do before you train." (participant 3, child).

Although the illness "took up space" and required careful planning, most children and parents felt that it did not prevent them from traveling and hanging out with friends. It was mostly the parents who took care of the practical parts and made sure everything was cared for.

"We travel to big cities, to beaches, and we have been to the United States. So far, we [the parents] are the ones doing the planning of all the things that should be brought. It's OK, but I don't think he knows how much we plan and think ahead." (participant 6, parent).

\subsection{The Importance of the Diabetes Team}

The views on the visits to the diabetes team varied for both parents and children. Many parents felt it was a positive experience and that it gave them a sense of security to meet the team and get information about values. Most importantly, the $\mathrm{HbAlc}$ value was the reward for being on the right track that you were a good parent. But even the children felt safe when the value was good, which meant less risk of complications and more security for the future. But there was also some concern before the visit, for example if the HbA1c value would be good or not. The responsibility for the HbAlc value was shared between children and parents, regardless of whether it was low or high. However, the children expressed less concern about test results than their parents.

"It feels good that I have got confirmation that what I'm doing is good, that's nice." (participant 4, child).

In particular, the parents experienced that they gained knowledge and feedback from the team staff, and this provided security. But they wanted more focus on the parenting situation. Some parents said that they lacked a parent forum, 
e.g. in the form of contact parents. The philosophy of the diabetes clinic is that the children should be independent at an early age and take responsibility for their illness. One parent said this was positive, while another felt that the child took responsibility too early.

"We have felt that this approach by the Children's Clinic to give the child more and more responsibility and backing down as a parent should be done without too much hurry. But maybe we can let them make mistakes sometimes, and then we can discuss it." (participant 3, parent).

We found that some children perceived the visits [to the clinic] as boring, predictable and meaningless, and they missed something fun at school. They thought they knew everything already.

"I just think it's a waste of time really. In any case, for the last few years, when I was doing well." (participant 2, child).

\section{Discussion}

\subsection{Methodology Discussion}

Several study limitations are noted. The participants were from similar backgrounds and live in the same geographical area. Most of the parents were female, which we could not influence as the sample was consecutive and the parents themselves decided who should participate. Probably, the results would have been different with more men or people of different ethnic backgrounds.

One inclusion criterion was that they should have had their illness for more than one year, but we have not taken into account how long they lived with their illness, which should affect how they and their family handle their life situation.

The authors are both qualified nurses, but have no specific experience of working with children and adolescents, which can be seen as an asset in the analysis. Another strength is that children and parents were interviewed at the same time, but separately so they could not influence each other's response. Furthermore, the interviews took place at a time and place that the children and their parents selected together. This should achieve maximum security, especially for the children.

\subsection{Results Discussion}

When a family member suffers from diabetes, the whole family is affected, which is particularly apparent in their everyday life. Routines, planning and advance measures will be important, and spontaneous activities may sometimes have less priority, which has been observed in earlier studies [5] [22]. Someone expressed this as a diabetes sorrow, to never feel really free. The worry among both children and parents was greater for hyperglycemia than for hypoglycemia, which contradicts other studies [11] [12] [13] [23]. This is possibly a message that the diabetes team has conveyed because the staff has a conscious striving to keep the children's HbA1c values down to avoid long-term complications [1]. It seemed harder for parents to accept that their children had a lifelong illness, and their 
worry about future complications was more apparent than the children's worry. The children lived more in the present and were pragmatic and did not worry about the future but solved care problems as they arose. Nearly all of the children interviewed had a high acceptance for living with diabetes and could therefore handle it in everyday situations.

Parents of children with chronic illness experience a poorer quality of life [24] and are at greater risk for burnout than parents of a healthy child [25]. It was mainly the mothers who reported these symptoms, and this may be because they take the most responsibility. However, there was no correlation between burnout and the children's HbA1c values. Mothers in this study expressed a need for increased psychosocial support from the diabetes team, which could reduce the risk of mental illness among parents of children with 1TDM. Also in Rankin's study, [14] the parents wanted a discussion about how life is affected, not just information about medical problems. Getting support from families in the same situation gives a sense of security, as they may get answers to questions and practical tips [26].

We found that the children in this study were focused, not only on their diabetes, but also on school work and hobbies. You may reflect on whether focused and structured individuals have low HbAlc values, or if it is their illness situation that makes them train these abilities and also benefit from this in other contexts. The relationship between children and parents appeared to be crucial to the security and well-being of both parties. Being able to trust each other and have a dialogue were success factors for the children's good health, which been known for a long time [18].

The motivation for all children to have low HbAlc values was greater than the inconvenience of pricking up to 10 times a day, which contradicts the results of a study by Maas-van Schaaijk et al. [6]. Pain affects the ability to independently check block sugar levels [5]. Since this study was conducted, most children and adolescents at the clinic have access to continuous blood sugar monitoring, which means that they do not have the discomfort of pricking any more. This should make it easier for them all to have HbAlc values within recommended levels, and not just the highly motivated ones.

The Diabetes team aims to ensure that children gradually become self-sufficient regarding the practical implementation of care for themselves, such as blood sugar checks and insulin administration. The children said that independence made them feel like "everyone else", and that this increased their sense of well-being. The parents felt that it was a tricky situation, whether they should give the children sufficient freedom while still having a controlling function.

\section{Conclusion}

This study shows that children with low HbAlc values experience good health and good well-being. Family support, good planning, and high acceptance of 
their illness contributed to this. A distinctive feature of the children in this study was that they were independent, focused and high-performing both at school and outside school hours. Both children and parents were satisfied with the medical care, but more parent support was requested.

\section{Relevance to Clinical Practice}

The findings highlight the importance for increased psychosocial support for both children and parents from the diabetes team. Greater flexibility from the diabetes team was requested, such as replacing some physical meetings with online meetings (Skype, Face-Time). Making fathers more involved in daily life is important for both children's and parents health and wellbeing.

\section{References}

[1] Donaghue, K.C., Wadwa, R.P., Dimeglio, L.A., Wong, T.Y., Chiarelli, F., Marcovecchio, M.L., et al. (2014) ISPAD Clinical Practice Consensus Guidelines 2014. Microvascular and Macrovascular Complications in Children and Adolescents. Pediatric Diabetes, 15, 257-269. https://doi.org/10.1111/pedi.12180

[2] Swedish Society for Diabetology (2017) NDR Nationella Diabetesregistret. Annual Report 2016, Göteborg.

[3] Lambert, V. and Keogh, D. (2015) Striving to Live a Normal Life: A Review of Children and Young People's Experience of Feeling Different When Living with a Long Term Condition. Journal of Pediatric Nursing, 30, 63-77. https://doi.org/10.1016/j.pedn.2014.09.016

[4] Freeborn, D., Dyches, T., Roper, S.O. and Mandleco, B. (2013) Identifying Challenges of Living with Type 1 Diabetes: Child and Youth Perspectives. Journal of Clinical Nursing, 22, 1890-1898. https://doi.org/10.1111/jocn.12046

[5] Sparapani Vde, C., Jacob, E. and Nascimento, L.C. (2015) What Is It Like to Be a Child with Type 1 Diabetes Mellitus? Pediatric Nursing, 41, 17-22.

[6] Maas-van Schaaijk, N.M.R.-V.A. and van Baar, A.L. (2013) The Interrelationships Among Paternal and Maternal Parenting Stress, Metabolic Control, and Depressive Symptoms in Adolescents With Type 1 Diabetes Mellitus. Journal of Pediatric Psychology, 38, 30-40. https://doi.org/10.1093/jpepsy/jss096

[7] Wake, M., Hesketh, K. and Cameron, F. (2000) The Child Health Questionnaire in Children with Diabetes: Cross-Sectional Survey of Parent and Adolescent-Reported Functional Health Status. Diabetic Medicine, 17, 700-707. https://doi.org/10.1046/j.1464-5491.2000.00360.x

[8] Anderson, B., Laffel, L., Domenger, C., Danne, T., Phillip, M., Mazza, C., et al. (2017) Factors Associated with Diabetes-Specific Health-Related Quality of Life in Youth with Type 1 Diabetes: The Global TEENs Study. Diabetes Care, 40, 1002-1009. https://doi.org/10.2337/dc16-1990

[9] Schmidt, C. (2007) Self-Care in Children with Type 1 Diabetes: A Survey of Mothers. MCN The American Journal of Maternal Child Nursing, 32, 223-229. https://doi.org/10.1097/01.NMC.0000281961.56207.9f

[10] Boogerd, E.A., Maas-van Schaaijk, N.M., Noordam, C., Marks, H.J. and Verhaak, C.M. (2015) Parents' Experiences, Needs, and Preferences in Pediatric Diabetes Care: Suggestions for Improvement of Care and the Possible Role of the Internet. A Qualitative Study. Journal for Specialists in Pediatric Nursing, 20, 218-229. 
https://doi.org/10.1111/jspn.12118

[11] Lawton, J., Waugh, N., Barnard, K.D., Noyes, K., Harden, J., Stephen, J., et al. (2015) Challenges of Optimizing Glycaemic Control in Children with Type 1 Diabetes: A Qualitative Study of Parents' Experiences and Views. Diabetic Medicine, 32, 1063-1070. https://doi.org/10.1111/dme.12660

[12] Marshall, M., Carter, B., Rose, K. and Brotherton, A. (2009) Living with Type 1 Diabetes: Perceptions of Children and Their Parents. Journal of Clinical Nursing, 18, 1703-1710. https://doi.org/10.1111/j.1365-2702.2008.02737.x

[13] Castensoe-Seidenfaden, P., Teilmann, G., Kensing, F., Hommel, E., Olsen, B.S. and Husted, G.R. (2017) Isolated Thoughts and Feelings and Unsolved Concerns: Adolescents' and Parents' Perspectives on Living with Type 1 Diabetes-A Qualitative Study Using Visual Storytelling. Journal of Clinical Nursing, 26, 3018-3030. https://doi.org/10.1111/jocn.13649

[14] Rankin, D., Harden, J., Waugh, N., Noyes, K., Barnard, K.D. and Lawton, J. (2016) Parents' Information and Support Needs When Their Child Is Diagnosed with Type 1 Diabetes: A Qualitative Study. Health Expectations: An International Journal of Public Participation in Health Care and Health Policy, 19, 580-591. https://doi.org/10.1111/hex.12244

[15] Quirk, H., Blake, H., Dee, B. and Glazebrook, C. (2014) "You Can't Just Jump on a Bike and Go": A Qualitative Study Exploring Parents' Perceptions of Physical Activity in Children with Type 1 Diabetes. BMC Pediatrics, 14, 313. https://doi.org/10.1186/s12887-014-0313-4

[16] Herbert, L.J., Clary, L., Owen, V., Monaghan, M., Alvarez, V. and Streisand, R. (2015) Relations among School/Daycare Functioning, Fear of Hypoglycaemia and Quality of Life in Parents of Young Children with Type 1 Diabetes. Journal of Clinical Nursing, 24, 1199-1209. https://doi.org/10.1111/jocn.12658

[17] Yi-Frazier, J.P., Hilliard, M.E., Fino, N.F., Naughton, M.J., Liese, A.D., Hockett, C.W., et al. (2016) Whose Quality of Life Is It Anyway? Discrepancies between Youth and Parent Health-Related Quality of Life Ratings in Type 1 and Type 2 Diabetes. Quality of Life Research: An International Journal of Quality of Life Aspects of Treatment, Care and Rehabilitation, 25, 1113-1121. https://doi.org/10.1007/s11136-015-1158-5

[18] Anderson, B., Ho, J., Brackett, J., Finkelstein, D. and Laffel, L. (1997) Parental Involvement in Diabetes Management Tasks: Relationships to Blood Glucose Monitoring Adherence and Metabolic Control in Young Adolescents with Insulin-Dependent Diabetes Mellitus. Journal of Pediatrics, 130, 257-265. https://doi.org/10.1016/S0022-3476(97)70352-4

[19] Ludvigsson, J. (2013) Is HbA1c $40 \mathrm{mmol} / \mathrm{mol}$ a Sign of Good Diabetes Care? Lakartidningen, 110, 928-929.

[20] Burnard, P. (1996) Teaching the Analysis of Textual Data: An Experiential Approach. Nurse Education Today, 16, 278-281. https://doi.org/10.1016/S0260-6917(96)80115-8

[21] Newell, R. and Burnard, P. (2006) Introduction to Nursing Research: Incorporating Evidence Based Practice. Blackwell Publishing, London.

[22] Smith, B.N., Bean, M.K., Mitchell, K.S., Speizer, I.S. and Fries, E.A. (2007) Psychosocial Factors Associated with Non-Smoking Adolescents' Intentions to Smoke. Health Education Research, 22, 238-247. https://doi.org/10.1093/her/cyl072

[23] Wang, Y.-L., Brown, S.A. and Horner, S.D. (2013) The School-Based Lived Experiences of Adolescents with Type 1 Diabetes. The Journal of Nursing Research, 21, 
235-243. https://doi.org/10.1097/jnr.0000000000000003

[24] van Nimwegen, K.J., Kievit, W., van der Wilt, G.J., Schieving, J.H., Willemsen, M.A., Donders, A.R., et al. (2016) Parental Quality of Life in Complex Paediatric Neurologic Disorders of Unknown Aetiology. European Journal of Paediatric Neurology, 20, 723-731. https://doi.org/10.1016/j.ejpn.2016.05.007

[25] Lindstrom, C., Aman, J. and Norberg, A.L. (2010) Increased Prevalence of Burnout Symptoms in Parents of Chronically Ill Children. Acta Paediatrica, 99, 427-432. https://doi.org/10.1111/j.1651-2227.2009.01586.x

[26] Rearick, E.M., Sullivan-Bolyai, S., Bova, C. and Knafl, K.A. (2011) Parents of Children Newly Diagnosed with Type 1 Diabetes: Experiences with Social Support and Family Management. The Diabetes Educator, 37, 508-518.

https://doi.org/10.1177/0145721711412979 